\title{
Multi-transgenic minipig models exhibiting potential for hepatic insulin resistance and pancreatic apoptosis
}

\author{
SIYUAN KONG, JINXUE RUAN, LEILEI XIN, JUNHUA FAN, JIHAN XIA, \\ ZHIGUO LIU, YULIAN MU, SHULIN YANG and KUI LI \\ State Key Laboratory of Animal Nutrition, Institute of Animal Sciences, \\ Chinese Academy of Agricultural Sciences, Beijing 100193, P.R. China
}

Received January 3, 2015; Accepted October 14, 2015

DOI: $10.3892 / \mathrm{mmr} .2015 .4582$

\begin{abstract}
There are currently no multi-transgenic minipig models of diabetes for the regulation of multiple genes involved in its pathogenesis. The foot and mouth disease virus $2 \mathrm{~A}$ (F2A)-mediated polycistronic system possesses several advantages, and the present study developed a novel multi-transgenic minipig model associated with diabetes using this system. The tissue-specific polycistronic system used in the present study consisted of two expression cassettes, separated by an insulator: (i) 11- $\beta$-hydroxysteroid dehydrogenase 1 (11 $\beta$-HSD1), driven by the porcine liver-specific apolipoprotein $\mathrm{E}$ promoter; (ii) human islet amyloid polypeptide (hIAPP) and C/EBP homologous protein (CHOP), linked to the furin digested site and F-2A, driven by the porcine pancreas-specific insulin promoter. In the present study, porcine fetal fibroblasts were transfected with this vector. Following somatic cell nuclear transfer using 10 cell clones and the transplantation of 1,459 embryos in total, three Landrace $x$ Yorkshire surrogates became pregnant and delivered three Wuzhishan piglets. Genomic polymerase chain reaction (PCR) demonstrated that the piglets were multi-transgenic. Reverse transcription-quantitative PCR confirmed that 11 $\beta$-HSD1 transcription was upregulated in the targeted liver. Similarly, hIAPP and CHOP were expressed at high levels, compared with the control $(\mathrm{P}<0.05$ and $\mathrm{P}<0.01)$ in the pancreas, consistent with the western blotting and immunohistochemistry results. The primary results also showed that overexpression of 11 $\beta$-HSD1 in the liver increased the liver fat lipid parameters; and the levels of hIAPP and CHOP in the pancreatic islet cells, leading to delayed $\beta$-cell development and apoptosis. This novel tissue-specific polycistronic system offers a promising starting point for efficiently mimicking multigenic metabolic disease.
\end{abstract}

Correspondence to: Dr Shulin Yang, State Key Laboratory of Animal Nutrition, Institute of Animal Sciences, Chinese Academy of Agriculture Sciences, 2 Yuanmingyuan West Road, Beijing 100193, P.R. China

E-mail: yangshulin@caas.cn

Key words: multi-transgene, polycistronic system, minipigs, somatic cell nuclear transfer, diabetes

\section{Introduction}

Diabetes mellitus involves the metabolism of various tissues and comprehensive signaling pathways. Type 2 diabetes is characterized by insulin resistance accompanied by inadequate insulin secretion (1). Investigations into the pathogenesis of diabetes and diabetes drug development has presented a requirement for suitable animal models. In the past two decades, several animal models have been established reflecting human disease pathogenesis from various perspectives $(2,3)$. Furthermore, animal models can assist in improving current understanding of the nature of a disease, and can provide a practical basis for the development of innovative therapies for preclinical experiments (4). With innovations in medicine and biotechnology, rodent models dominate this field. However, pigs are more similar to humans than rodents in terms of genetics, morphology, anatomy, physiology, dietary habits and pharmacokinetics (5), and minipigs are particularly useful due to their advantages of a small size and ease of handling. Thus, minipig models have emerged as an ideal tool in translational medicine (6).

However, minipig models are not ideal for constructing metabolic disease models through diet or drug induction. Certain disease models are induced through diet over a long duration (7-10), whereas a transgenic animal offers the potential for a shorter induction duration. Disease models generated by drug induction, examine only one aspect, for example a type 2 diabetes model induced by STZ, which involves pancreatic damage, leading to insulin deficiency (11). Therefore, multi-transgenic models enable a more comprehensive analysis of pathology. Several multi-transgenic pigs have been developed for disease models and animal breeding (12-15). In addition, polygenic modified porcine models have extensive and more efficient potential, compared with single transgenic pigs (12). Dieckhoff et al used multi-transgenic pigs for a series of investigations on retroviruses. These polygenic pigs were obtained by crossbreeding single transgenic pigs (13). In addition, Webster et al incubated sperm cells with three marker vectors and generated multi-transgenic fluorescent pigs (14). To simplify vector construction procedures; increase modeling efficiency, stability and integrated uniformity; and reduce the difficulty of transfection, several studies have attempted to use polycistronic vectors to load multiple genes. Deng et al adopted 
a single vector with $2 \mathrm{~A}$ peptides linking four marker genes, to prepare multi-transgenic fluorescent pigs (12). Jeong et al used an internal ribosome entry site (IRES)-mediated polycistronic vector to co-express human CD59, CD55 and H-transferase in Yucatan minipig models (15). Park et al also used the 2A peptide to generate shTNFRI-Fc and HA-hHO-1 Yucatan transgenic (Tg) pigs (16). However, there have been no previous reports of a multi-transgenic porcine diabetes model. Therefore, the present study aimed to create a multi-transgenic minipig diabetes model, which can express functional genes directly through a foot and mouth disease virus $2 \mathrm{~A}$ (F2A)-mediated polycistronic system.

In pilot investigations, diabetic pig models have been successfully manufactured by alteration of a single important gene $(3,17-19)$. However, to develop a model involving the alteration of multiple crucial genes, the present study selected three genes: 11- $\beta$-hydroxysteroid dehydrogenase 1 (11 $\beta$-HSD1), which is involved in insulin resistance (20); human islet amyloid polypeptide (hIAPP) (3) and C/EBP homologous protein (CHOP) (21), which can disrupt the islets. The present study aimed to investigate whether increased hepatic production of glucocorticoid, catalyzed by $11 \beta$-HSD1 directly, induces insulin resistance with adipose deposition, and whether elevated expression levels of hIAPP and CHOP lead to pancreatic cell damage in the animals. Ideally, the multi-transgenic pig islet $\beta$-cell stress-associated apoptosis pathways are activated (22), which thereby enable a reduction in the number of islet $\beta$-cells, resulting in the absolute lack of insulin secretion (23). In addition, insulin resistance is caused by $11 \beta-H S D 1$ (24) and significantly impaired glucose tolerance, with consistently high levels of fasting glucose in the future (20), culminating in generating the diabetes model. The model aims to support investigations of the mechanisms involved these two pathways (25), and may also be used for developing novel drugs, with $11 \beta$-HSD1 as a target, for the treatment of diabetes, Cushing's syndrome and other metabolic diseases (26), and for developing drugs to promote insulin secretion $(25,27)$.

\section{Materials and methods}

Experimental animals. The donor cells for use in in vitro somatic cell nuclear transfer (SCNT) were porcine fetal fibroblasts (PFFs) obtained 35 day fetuses from Wuzhishan miniature pigs (WZSPs). The WZSPs used in the present study were obtained from the Germplasm Resource Center of Chinese Experimental Minipig at the Institute of Animal Sciences, Chinese Academy of Agricultural Sciences (Beijing, China). The recipient animals were Landrace $\mathrm{x}$ Yorkshire pigs (8-month-old females; Tianjing Yililai Breeding Co., Ltd., Tianjin, China), and received humane care according to the criteria outlined in the Guide for the Care and Use of Laboratory Animals, Institute of Animal Sciences, Chinese Academy of Agricultural Sciences (Beijing, China). The procedures were approved by the Institute of Animal Sciences, Chinese Academy of Agricultural Sciences (Beijing, China; permit no. ACGRCM2013-035). All animals were housed under controlled conditions (temperature, $18-22^{\circ} \mathrm{C}$; relative air humidity, 30-70\%) with free access to water. The animals were sacrificed through overdose of ketamine $(100 \mathrm{mg} / \mathrm{kg}$; cat. no. 087K1253; Sigma-Aldrich, St. Louis, MO, USA) and xylazine (25 mg/kg; cat, no. KH070901; Hengrui,Lianyungang, China). The tissues were immediately frozen in liquid nitrogen and stored at $-80^{\circ} \mathrm{C}$ for subsequent analysis.

Construction of a multi-transgenic tissue-specific polycistronic system. A recombinant plasmid vector (Fig. 1) containing multiple genes (11 $\beta$-HSD1, CHOP and hIAPP) was constructed based on pcDNA3.1c (+) (cat. no. V790-20; Invitrogen; Thermo Fisher Scientific, Inc., Waltham, MA, USA). This vector consisted of two expression cassettes separated by a matrix-attachment region (MAR) insulator (28). One cassette carried the porcine liver-specific apolipoprotein $\mathrm{E}$ promoter (PapoE) (29) and porcine 11 $\beta$-HSD1 cDNA (GenBank: NM_214248.1), and the other cassette contained the porcine pancreas-specific insulin promoter (PIP), which was cloned by designed primers basing on the GenBank human counterpart, and the murine CHOP (GenBank: NM_007837.3) and human IAPP (GenBank: NM_000415.2) cDNAs. The foot and mouth disease virus $2 \mathrm{~A}$ sequence (F-2A fragment) following the furin digested site (5'-ATCACGAATTCCAGCTGTTGAATTTTG ACCTTCTTAAGCTTGCGGGAGACGTCGAGTCCAACC CCGGGCCCGAATTCGTCGAGACC-3') linked CHOP with IAPP. All sequences between PapoE and bovine growth hormone polyadenylation signal were synthesized (Invitrogen; Thermo Fisher Scientific, Inc.). In addition, MluI and NotI restriction sites were designed to locate the start and end of this synthesized fragment, respectively. The multiple cloning site of pcDNA3.1 (+) was digested using the MluI and NotI enzymes (New England Biolabs, Beijing, China), and the cytomegalovirus (CMV) promoter fragment was replaced with this synthesized fragment. Thus, the present study successfully generated the pcDNA3.1-PapoE-HSD11B1-PIP-CHOP-IAPP recombinant vector. The recombinant DNA molecular was digested using the endonuclease, ScaI (New England Biolabs), and the excised fragment was separated by agarose gel electrophoresis (Biowest Regular Agarose G-10 Biowest, Hongkong, China). Purification (Zymoclean Gel DNA Recorvery Kit ${ }^{\mathrm{TM}}$; cat. no. D4008; Zymo Research Corporation, Irvine, CA, USA) and sequencing (Invitrogen; Thermo Fisher Scientific, Inc.) was performed for verification. This strategy successfully generated the pcDNA3.1-PapoE-11 $\beta$-HSD1-PIP-CHOPhIAPP recombinant vector (Fig. 1).

Transfection of PFFs and preparation of in vitro maturation enucleated oocytes. A linear DNA molecule was generated using the ScaI endonuclease to digest the recombinant vector for extraction from agar gel electrophoresis (Zymoclean Gel DNA Recorvery $\mathrm{Kit}^{\mathrm{TM}}$; cat. no. D4008). At 35 days following the birth of the WZSPs, PFFs were digested with $0.25 \%$ trypsin (Yaxin Biotechnology, Co., Ltd., Shanghai, China) at $37^{\circ} \mathrm{C}$ and cultured in complete culture medium, containing DMEM (cat. no. D5648; Sigma-Aldrich), $2 \mathrm{~g} / \mathrm{L} \mathrm{NaHCO}_{3}$ (cat. no. S5761; Sigma-Aldrich), 15-20\% fetal bovine serum (FBS; cat. no. 16000-044; Sigma-Aldrich), 1\% penicillin-streptomycin (cat. nos. P7794 and S1277-5G; Sigma-Aldrich). Routine steps of cell recovery, passage and cryopreservation were adopted, following which electroporation was performed following transfection $(12,15,30)$. At $2-4$ days prior to transfection, the PFFs were thawed and subcultured at $37^{\circ} \mathrm{C}$ in 
complete culture medium with $15 \%$ FBS $\left(1-2 \times 10^{6}\right.$ cells per well) until the cells reached $70-90 \%$ confluence, the cells were trypsinized and planked in cell board. Generally, the required number of cells per well was $0.5-1 \times 10^{6}$ following primary cell counting, and $2 \mu \mathrm{g}$ pcDNA3.1-PapoE-HSD11B1-PIP-C HOP-IAPP was used per well. The reaction required $100 \mu \mathrm{l}$ electroporation solution (BTX Technologies, Inc., Hawthorne, NY, USA), comprising $82 \mu 1$ Nucleofector ${ }^{\circledR}$ solution and $18 \mu \mathrm{l}$ supplement. Electroporation was performed, according to the manufacturer's instructions (Lonza Group, Basel, Switzerland) to select the optimal transfer program (T-016). Following electroporation, the cells were transferred to the cell incubator and incubated at $37^{\circ} \mathrm{C}$ for $48 \mathrm{~h}$, seeded directly into a 96-well cell plate (500-1,000 cells/well) (30). During the first 2 days, the cells were selected using $800 \mathrm{ng} / \mu \mathrm{l} \mathrm{G} 418$ (Merck Millipore, Beijing, China), and were then screened with a concentration of $600 \mathrm{ng} / \mu \mathrm{l}$ in the following 10 days. In the last 3 days, the G418 concentration was reduced to $200 \mathrm{ng} / \mu 1$. G428 selection continued for 15 days. Following G418 screening and colony formation, positive cells were identified and expanded in order to select optimally growing clones to perform SCNT.

Ovaries were collected from the Yorkshire pigs in a slaughter house (Beijing Shunyi Slaughter Company, Changping, Beijing, China). The blood and other contaminants were removed by washing in preheated double-antibiotic normal saline (penicillin and streptomycin) three to four times. The cumulus-oocyte complexes (COCs) and follicular fluid were collected from 3-6 mm (diameter) follicles. A $10 \mathrm{ml}$ disposable syringe with a $12^{\#}$ needle were used, and the needle opening was directed downwards when inserted into the side tissues of the follicle. The follicular fluid was transferred into $50 \mathrm{ml}$ centrifuge tubes for $15-20 \mathrm{~min}$ at $25^{\circ} \mathrm{C}$, following which the supernatant was discarded. Subsequently, the precipitation was washed 2-4 times using $38^{\circ} \mathrm{C}$ polyvinyl alcohol-Tyrode's lactate-Hepes (PVA-TL-HEPES) medium (Nunc, Vedbaek, Denmark), with the supernatant carefully discarded after standing for $10 \mathrm{~min}$ each time. The washed follicular fluid ( $\sim 6 \mathrm{ml})$ was transferred to $60 \mathrm{~mm}$ Petri dishes. Under a stereoscope (SMZ1500; Nikon, Tokyo, Japan), oocytes were picked up using a mouth pipette and transferred onto a $35 \mathrm{~mm}$ Petri dish prefilled with PVA-TL-HEPES, then washed twice. In the washing process, COCs surrounded by three or more layers of cumulus cells were selected under a dissecting microscope (SZX7; Olympus Corporation, Toyko, Japan), which had a regular shape, uniform cytoplasm and were diaphanous. The oocytes were washed with PVA-TL-HEPES twice in a $35 \mathrm{~mm}$ petri dish and transferred to another dish containing balanced free-hormone Tissue Culture Medium 199 solution (Gibco; Thermo Fisher Scientific, Inc.) and washed twice again. Consequently, 60-80 oocytes/well were distributed into a 4-well plate, under conditions of $38.5^{\circ} \mathrm{C}, 5 \% \mathrm{CO}_{2}$ and saturated humidity for $40 \mathrm{~h}$. MII oocytes with an integrated vitelline membrane, clear perivitelline space, symmetrical cytoplasm and a conspicuous polocyte were selected for SCNT (31).

SCNT and the generation of multi-transgenic pigs. Positive PapoE-11 $\beta$-HSD1-PIP-CHOP-hIAPP WZS PFFs served as nuclear donor cells. Initially, the first polar body and a section of the surrounding cytoplasm of the MII oocytes were drawn out using a microinjection needle. Secondly, positive cells were injected into the perivitelline space at the same location of the oocyte. The reconstructed oocyte-donor cell complexes were fused and activated by electric shock (CF-150B; BIological Laboratory Equipment, Maintenance and Service, Ltd., Budapest, Hungary). The activated complexes were placed in PZM3 culture medium (Greiner Bio One, Frickenhausen, Germany) and cultivated at $38^{\circ} \mathrm{C}$ in $5 \% \mathrm{CO}_{2}$ for 9 days. Finally, well-developed embryos with the desired shapes were selected for implantation. Caesarean surgery and eutocia were combined $\sim 114$ days later, based on pregnancy status, to deliver the piglets.

Sample collection. Of the piglets examined, one piglet was sacrificed 8 days following birth, and another was stillborn. The ears were removed and placed in $75 \%$ ethanol. The pancreas, left lobe of liver, kidneys and longissimus muscles were dissected, samples of which were rapidly frozen in liquid nitrogen. The remaining tissue samples were fixed in $4 \%$ paraformaldehyde (cat. no. P1110; Solarbio, Beijing, China).

RNA isolation, cDNA preparation and total protein extraction. The liquid nitrogen-frozen tissues were triturated in duplicate using a Precellys 24 homogenizer (Bertin Technologies, Montigny-le-Bretonneu, France) and were used for RNA extraction and total protein isolation. Total RNA was extracted using TRIzol reagent (Ambion; Thermo Fisher Scientific, Inc.), according to the manufacturer's protocol. The remaining genomic DNA was eliminated using DNase I (Tiangen Biotech Co., Ltd., Beijing, China), and cDNAs were reverse-transcribed from the total RNA using a Revert Aid First Strand cDNA Synthesis kit (Thermo Fisher Scientific, Inc.). The conditions were as follows: $5 \mathrm{~min}$ at $37^{\circ} \mathrm{C}$, followed by $60 \mathrm{~min}$ at $42^{\circ} \mathrm{C}$ and $10 \mathrm{~min}$ at $72^{\circ} \mathrm{C}$. The cDNA samples were cooled at $-20^{\circ} \mathrm{C}$ as soon as possible, and were used to evaluate the transcriptional expression of target genes using quantitative polymerase chain reaction (qPCR) analysis.

Total protein was obtained from the tissues using T-PER Tissue Protein Extraction reagent (Thermo Fisher Scientific, Inc.). In addition, protease inhibitor containing cocktail tablets (cat. no. 4693159001; Roche Diagnostics GmbH, Mannheim, Germany) was used to protect protein integration. The total protein concentration was determined using Working reagent (Thermo Fisher Scientific, Inc.) and ELISA (Spectra Max M5; Molecular Devices; Thermo Fisher Scientific, Inc. Following SDS degeneration, the protein solution was stored at $-20^{\circ} \mathrm{C}$ for subsequent western blot analysis.

$P C R$ and $q P C R$ analysis. Genomic DNA was isolated from the ear clippings of the WZS Tg and non-Tg piglets (BioTeke Corporation, Beijing, China). PCR was used to screen the positive PFFs and to identify multi-transgenic piglets. The PCR primers were designed using Primer Premier 5.0 software (Premier Biosoft International, Palo Alto, CA, USA). A total of four primer pairs (Table I) were used for these amplifications. PCR was performed in a $20 \mu \mathrm{l}$ system, containing $2 \mu \mathrm{l}$ 20X PCR buffer $\left(\mathrm{Mg}^{2+}\right), 100 \mu \mathrm{mol} / 1 \mathrm{dNTP}, 1 \mu \mathrm{mol}$ of each PCR primer, 2X U Taq DNA polymerase (Takara Biotechnology Co., Ltd., Dalian, China) and $2 \mu \mathrm{l}$ DNA derived from the PFF clone or WZS multi-transgenic piglet ears. The PCR program was as follows: $95^{\circ} \mathrm{C}$ for 5 min denaturation, 35 cycles of $94^{\circ} \mathrm{C}$ for 
Table I. Primers used for multi-transgenic identification and gene expression analysis.

\begin{tabular}{|c|c|c|c|c|}
\hline Primer & Sequence $\left(5^{\prime}-3^{\prime}\right)$ & $\begin{array}{l}\text { Temp } \\
\left({ }^{\circ} \mathrm{C}\right)\end{array}$ & $\begin{array}{c}\text { Product } \\
\text { length (bp) }\end{array}$ & Use \\
\hline PapoE-11b F & GCTСССТTТСССССТТААСС & 60 & 513 & Analysis of Tg PFFs and pigs \\
\hline PapoE-11b R & AGGCCAAGAAGATCCCCAGA & & & \\
\hline PIP-CHOP F & AGGGAAATGATCCAGAAAGTGC & 57 & 506 & Analysis of Tg PFFs and pigs \\
\hline PIP-CHOP R & GGACGCAGGGTCAAGAGTAGTG & & & \\
\hline CHOP-IAPP F & GAAACGGAAACAGAGTGG & 57 & 445 & Analysis of Tg PFFs and pigs \\
\hline CHOP-IAPP R & GTTGCTGGAATGAACTAAAA & & & \\
\hline IAPP-pA F & TCATCAGGTGGAAAAGCGGAA & 65 & 423 & Analysis of Tg PFFs \\
\hline IAPP-pA R & TAGCCAGACCATAGAGCCCA & & & \\
\hline $11 \beta 35-\mathrm{F}$ & AGACACAGACACGGCCATGA & 59 & 62 & $\begin{array}{l}\text { Analysis of copy number and } \\
\text { gene expression }\end{array}$ \\
\hline $11 \beta 35-\mathrm{R}$ & TTCGGAGATGGTTGTACGTTGA & & & \\
\hline CHOP 206-F & CAACAGAGGTCACACGCACAT & 58 & 69 & $\begin{array}{l}\text { Analysis of copy number and } \\
\text { gene expression }\end{array}$ \\
\hline CHOP 206-R & CCTGGGCCATAGAACTCTGACT & & & \\
\hline IAPP75 short-F & TGAAAGTCATCAGGTGGAAAAGC & 59 & 60 & $\begin{array}{l}\text { Analysis of copy number and } \\
\text { gene expression }\end{array}$ \\
\hline IAPP75 short-R & AGGCGCTGCGTTGCA & & & \\
\hline GAPDH-F & AGGGCATCCTGGGCTACACT & 60 & 166 & Reference for gene expression \\
\hline GAPDH-R & TCCACCACCCTGTTGCTGTAG & & & \\
\hline TFRC-F & GAGACAGAAACTTTCGAAGC & 60 & 81 & Reference for copy number \\
\hline TFRC-R & GAAGTCTGTGGTATCCAATCC & & & \\
\hline
\end{tabular}

11 $\beta$-HSD1, 11- $\beta$-hydroxysteroid dehydrogenase 1; CHOP, C/EBP homologous protein; IAPP, islet amyloid polypeptide; F, forward primer; $\mathrm{R}$, reverse primer; PapoE, porcine apolipoprotein E promoter; PIP, porcine insulin promoter; PFFs, porcine fetal fibroblasts; Temp, annealing temperature; bp, base pair.

30 min denaturation, $60^{\circ} \mathrm{C}$ for $30 \mathrm{sec}$ annealing, $72^{\circ} \mathrm{C}$ for $30 \mathrm{sec}$, followed by a final extension of $5 \mathrm{~min}$ at $72^{\circ} \mathrm{C}$. All reactions were performed in duplicate. The products were stained with Gel Red (Generay Biotech Co., Ltd., Shanghai, China) and analyzed using $1 \%$ agarose gel electrophoresis (G-10; Biowest). qPCR was performed to determine the levels of expression of the transcriptional genes, which was performed using an ABI PRISM ${ }^{\circledR} 7500$ Real-Time PCR system to determine the transcriptional expression of the transgenes in the liver, pancreas, muscle (longissimus dorsi) and kidney. SYBR ${ }^{\circledR}$ Premix Ex Taq ${ }^{\mathrm{TM}}$ reagent and ROXII calibrating liquid (Takara Biotechnology Co., Ltd.) was also used. The forward and reverse primers are listed in Table I. Each qPCR reactive mixture contained $10 \mu 1 \mathrm{SYBR}^{\circledR}$ Premix Ex $\operatorname{Taq}^{\mathrm{TM}}(2 \mathrm{x}), 0.8 \mu \mathrm{l}$ forward and reverse primers $(10 \mu \mathrm{M}$; Table I), $0.4 \mu \mathrm{l}$ ROXII, $2 \mu \mathrm{l}$ DNA templates and $\mathrm{dH}_{2} \mathrm{O}$, to total volume of $20 \mu \mathrm{l}$. The qPCR analysis was performed as a two-step procedure: Stage 1, initial denaturation of $30 \mathrm{sec}$ at $95^{\circ} \mathrm{C}$; stage 2, PCR reaction, comprising 40 cycles of $5 \mathrm{sec}$ at $95^{\circ} \mathrm{C}$ and $34 \mathrm{sec}$ at $60^{\circ} \mathrm{C}$; stage 3 , dissociation stage comprising $15 \mathrm{sec}$ at $95^{\circ} \mathrm{C}$, $1 \mathrm{~min}$ at $60^{\circ} \mathrm{C}$ and $15 \mathrm{sec}$ at $95^{\circ} \mathrm{C}$. All reactions were performed in triplicate. ABI 7500 System SDS software (Version 1.4) was used to analyze the data. Amplification plots were constructed to reflect the gene amplification status. The specificity of the primers with the cDNA templates were determined from the dissociation melting curve, which ideally had only one peak. Quantification of target gene expression levels were calculated by the comparative threshold $(\mathrm{Ct})$ value, the expression levels of all transgenes were normalized to that of the porcine glyceraldehyde-3-phosphate dehydrogenase (GAPDH) mRNA Ct value and expressed as $2^{-\Delta \Delta C t}(32)$

Multi-transgene copy number determination. qPCR with the $\Delta \mathrm{Ct}-\log _{\mathrm{a}} \mathrm{N}$ absolute standard curve method was used to determine copy numbers (33). $\Delta \mathrm{Ct}$ was defined as $\mathrm{Ct}_{\text {[transgene] }}-\mathrm{Ct}_{\text {[transferrin receptor (TFRC)] }}$. TFRC is known to exist as a single copy in the porcine haploid genome and is used as a reference gene (34). The primers, which were used to amplify TFRC are listed in Table I. A mixed gradient copy number standard was used for standardization $\left(\mathrm{N}=10^{5}, 10^{4}, 10^{3}, 10^{2}\right.$, $10,1$ or $64,32,16,8,4,2,1,0.5)$, with $100 \mathrm{ng}$ of wild-type genomic DNA. Standard curves were constructed to clarify the correlation between $\Delta \mathrm{Cq}$, and the $\lg \mathrm{N}$ or $\log _{2} \mathrm{~N}$ and calculated the copy number of target genes, respectively.

Western blot analysis. The expression levels of Tg proteins were measured in the tissue samples from the liver and pancreas of the multi-transgenic piglets. High-quality protein was extracted using Tissue Protein Extraction Reagent (T-PER; Thermo Fisher Scientific, Inc.). Protease inhibitors (Roche Diagnostics $\mathrm{GmbH}$ ) were added to the T-PER reagent, just prior to use. The tissues were homogenized in this lysis buffer (cat. no. 78510; Thermo Fisher Scientific, Inc.) using pellets and the sample 


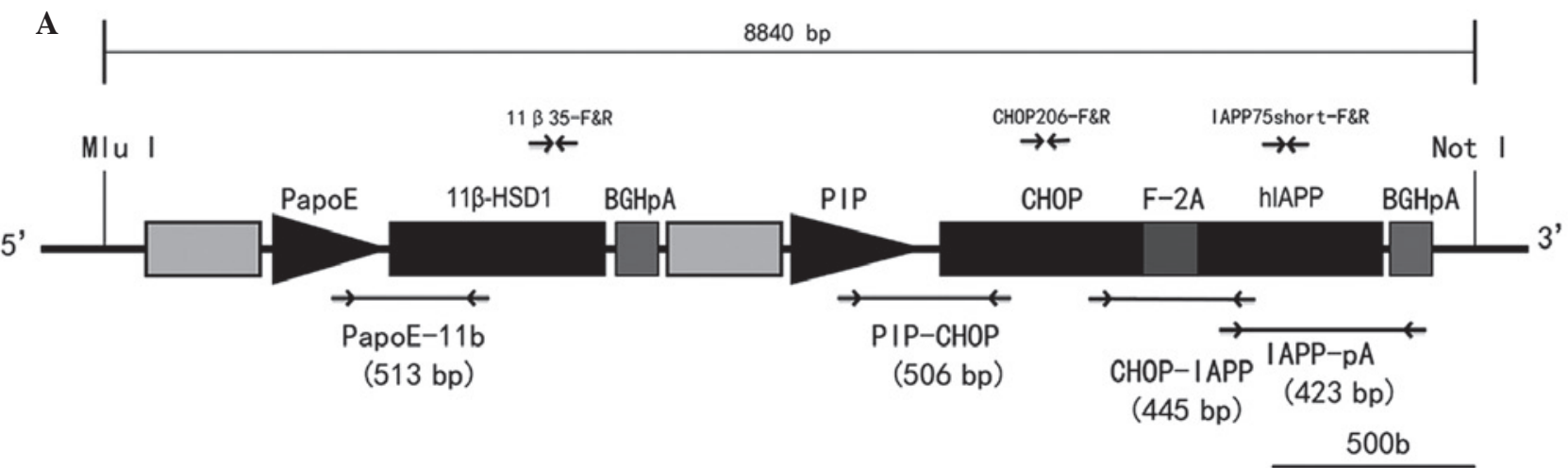

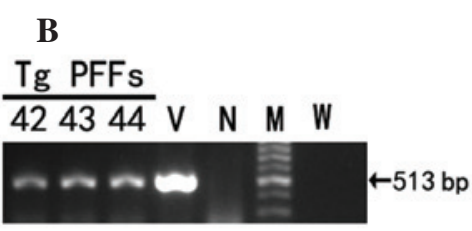

PapoE-11b

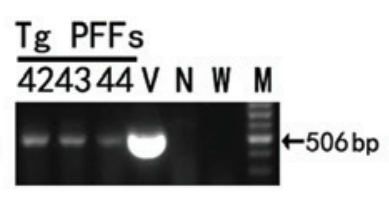

PIP-CHOP

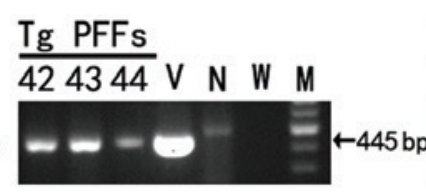

CHOP-IAPP
Tg PFFs 424344 V N M W
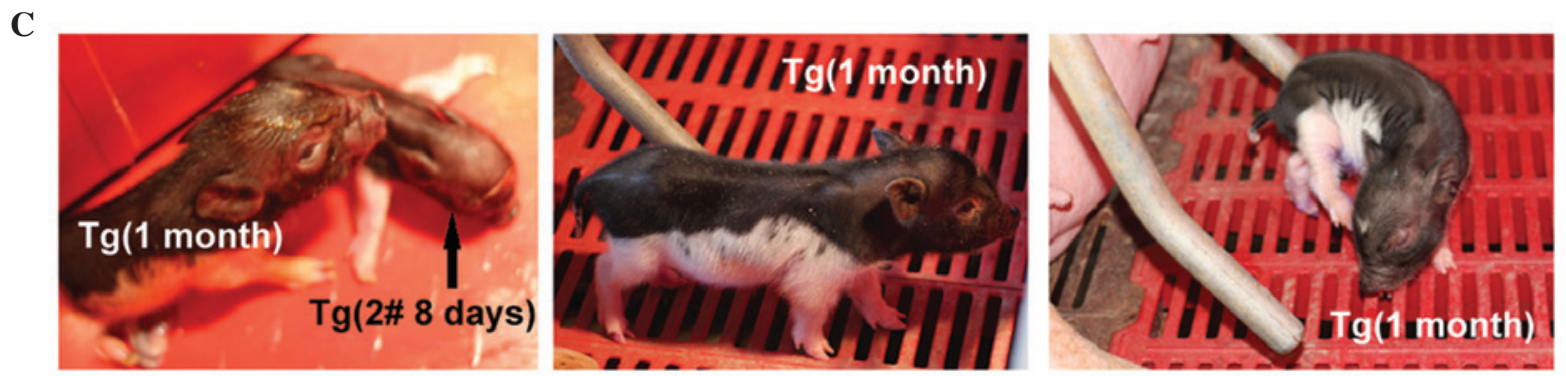

D

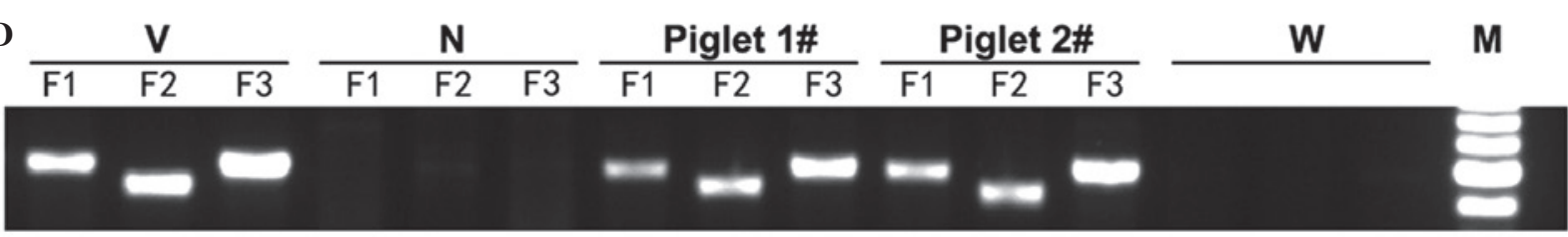

Figure 1. Generation and identification of multi-transgenic PFFs and minipigs. (A) Schematic structure of tissue-specific polycistronic system (8,840 bp). The head-to-head arrows represent the primers for transgenic recognition, copy number measurement and gene expression analysis. The fragment between the two restriction sites comprises two cassettes isolated by an insulator: (1) 11 $\beta$-HSD1 driven by the liver-specific PapoE; (2) hIAPP and CHOP linked to the F-2A peptide driven by the PIP. (B) PCR screening of multi-transgenic PFFs. Amplification of the PapoE-11b, PIP-CHOP, CHOP-IAPP and IAPP-pA fragments is shown, respectively. Lanes 42-44, three representative PFFs transfected by the vector. (C) Multi-transgenic piglets produced by somatic cell nuclear transfer. (D) Genomic DNA PCR identification of piglet $1^{\#}, 2^{\#}$ and negative control. F1-F3 indicate the three anticipated bands corresponding to PapoE-11b, PIP-CHOP and CHOP-IAPP, respectively. Tg, transgenic; $11 \beta$-HSD1, $11-\beta$-hydroxysteroid dehydrogenase 1 ; PapoE; hIAPP; human islet amyloid polypeptide; PIP, porcine pancreas-specific insulin promoter; $\mathrm{CHOP}$; C/EBP homologous protein; PCR, polymerase chain reaction; V, positive vector; N, negative control; M, 100 bp DNA ladder; W, ddH2O. MluI, MluI restriction enzyme site; NotI, NotI restriction enzyme site; PFFs, porcine fetal fibroblasts.

was centrifuged at $10,000 \mathrm{xg}$ for $5 \mathrm{~min}$ at $4^{\circ} \mathrm{C}$. The supernatant was collected and protein concentration was determined using a Micro BCA Protein Assay kit (Pierce Biotechnology, Inc., Rockford, IL, USA). An equivalent quantity of protein $(27 \mu \mathrm{g})$ was loaded in each lane, separated by SDS-PAGE, and then transferred onto a nitrocellulose membrane by electroblotting. The membrane was blocked with $5 \%$ fat-free milk or bovine serum albumin (BSA), following which the membranes were incubated with primary antibodies against $11 \beta$-HSD1 (polyclonal rabbit anti-pig; 1:1,000 dilution; cat. no. ab83522; Abcam, Cambridge, MA, USA), CHOP (monoclonal rabbit anti-mouse; 1:1,000 dilution; cat. no. ab11419; Abcam), hIAPP (polyclonal rabbit anti-human; 1:500 dilution; sc-20936; Santa Cruz Biotechnology, Inc., Santa Cruz, CA, USA) and $\beta$-actin (polyclonal rabbit anti-mouse; 1:1,000 dilution; cat. no. TA-09; Zhongshan Biotech Co., Ltd., Beijing, China). Subsequently, the membranes were incubated with a horseradish peroxidase-conjugated goat anti-rabbit antibody (1:5,000 dilution; cat. no. ab97051; Abcam) for $1 \mathrm{~h}$ at room temperature. Following washing, the immunoblots were detected using Super Signal West Pico Chemiluminescent substrate (Thermo Fisher Scientific, Inc.).

Hepatic lipid biochemistry. The liver tissues (1\#: $64.7 \mathrm{mg}$; $2^{\#}: 77 \mathrm{mg}$, Nc: $52 \mathrm{mg}$ ) were thoroughly homogenized in $1,000 \mu 1$ normal saline using procedure $1(5000-2 \times 10-030)$ in a Precellys 24 homogenizer (Bertin Technologies), and the debris precipitate was removed by centrifugation at $12,000 \mathrm{rpm}$. 
Subsequently, $800 \mu 1$ of the supernatant was used to assay the triglyceride and total cholesterol contents via the oxidase method (17082 Hitachi Automatic Biochemical Analyzer; Hitachi, Tokyo, Japan) (35). The concentration of cortisol in the hepatic tissue was determined via electrochemiluminescence using an automatic electrochemical luminescence analyzer (Elecsys2010; Roche Diagnostics GmbH). The final values were converted to comparable proportions.

Immunohistochemistry. The tissues were sliced $(5 \mu \mathrm{m})$ following $4 \%$ paraformaldehyde treatment and being embedded in paraffin. The sections were stained with hematoxylin (5\%; Solarbio) and eosin using routine method. An anti-insulin antibody (anti-pig insulin; 1:300 dilution; Abcam) was used for the immunohistochemical localization of the pancreas islets. Primary antibodies against CHOP (1:50 dilution; Abcam) were used to validate transgene overexpression. Pancreatic apoptosis was analyzed using blotting with anti-caspase 3 antibody (1:400 dilution; Abcam). The paraffin-embedded pancreas sections of the $\mathrm{Tg}$ and negative control $(\mathrm{Nc})$ animals were stained with the indicated antibodies. The primary antibody was incubated for $1.5 \mathrm{~h}$ at room temperature, followed by incubation with the secondary antibody (Abcam). Diaminobenzidine (Sigma-Aldrich) served as the color development reagent. Finally, hematoxylin was used to counterstain the sections. An Olympus microscope (CX31; Olympus Corporation) connected to a Pixera digital camera (Pro 120es; Pixera Corporation, San Jose, CA USA) was used to capture images of the sections.

Statistical analysis. The data are presented as the mean \pm standard error of mean. Two-sample unpaired two-tailed t-tests were used to measure the statistical significance of differences (Microsoft Office Excel 2010; Microsoft Corporation, Redmond, WA, USA). $\mathrm{P}<0.05$ was considered to indicate a statistically significant difference.

\section{Results}

Transgenesis of PFFs and screening of positive cells. The linearized pcDNA3.1-PapoE-11 $\beta$-HSD1-PIP-CHOP-hIAPP was introduced into porcine PFFs by electroporation (Fig. 1A). Stably transfected PFFs were selected with G418 for 15 days. PCR was used to verify the multi-transgenic PFFs (Fig. 1B). When all target fragments co-occurred, the PFFs were identified as Tg. Clones 1-44 had successful integration events, and nine of these clones with high-efficiency amplification were selected to prepare SCNT embryos.

Development of SCNT embryos in vivo and generation of multi-transgenic WZS miniature piglets. A total of 1,459 Tg-SCNT embryos were produced and surgically transplanted into the fimbriae of the fallopian tubes of three naturally estrous Landrace x Yorkshire gilts (Table II). Two recipients became successfully pregnant, and another one returned to estrus. The first surrogate mother delivered a live pigletby eutocia (Fig. 1C Tg; 1 month). The second gilt gave birth to two babies by caesarean, including one stillborn piglet (not shown, but termed piglet $1^{\#}$ ) and one, which was sacrificed at 8 days old due to feeding difficulty and artificial feeding indigestion (Fig. 1C $\mathrm{Tg}\left(2^{\sharp} ; 8\right.$ days). Caesarean

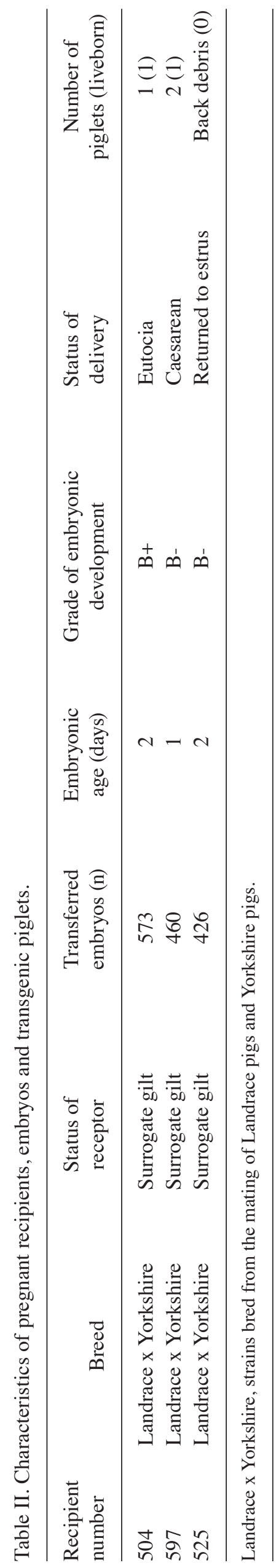


section was also performed in the third recipient; in which a mass of black-brown debris was found and surgically removed (Table II). Unfortunately, the eldest ( $\mathrm{Tg} ; 1$ month) did not survive as a result of umbilical cord inflammation.

Genotyping of multi-transgenic pigs and determination of transgene copy numbers. Genomic DNA was extracted from the ear clippings of piglets $1^{\#}, 2^{\#}$ and the Nc. Three primer pairs (Table I) were used to amplify three segments to confirm the presence of the three exogenous genes in the multi-transgenic pigs $\left(1^{\#}\right.$ and $\left.2^{\#}\right)$ when the three aim bands emerged at the same time (Fig. 1D). Copy number determination in single-transgenic pigs is being increasingly reported $(24,35)$. However, there are few reports in multi-transgenic animals. This approach revealed very notable and inconsistent results in the polycistronic system-transfected pigs in the present study (Fig. 2 and Table III).

Overexpression of the three transgenes in specific tissues of different individuals. Piglets $1^{\#}$ and $2^{\#}$ were used to examine the transcription and translation of target genes. Piglet $1^{\#}$ was stillborn, and piglet $2^{\#}$ was sacrificed at 8 days old. Secretion insufficiency and insulin resistance-associated tissues, including the pancreas, liver, muscle and kidney, were used for analysis. The transcriptional expression levels of the three genes were determined by qPCR in various individuals and organs (Fig. 3A-C). These results indicated that the transgenes were overexpressed, and that the PapoE and PIP worked. The relative mRNA levels of $11 \beta$-HSD1 in piglet $2^{\#}$ were almost two-fold those of the piglets in the Nc group (Fig. 3A; left). As piglet $1^{\#}$ was stillborn, its mRNA was more likely to be degraded, and the gross expression of $11 \beta-H S D 1$, including endogenesis and $\mathrm{Tg}$ exogenesis, was low (Fig. 3A; left). The levels of CHOP and hIAPP were high in the positive piglets $\left(1^{\#}\right.$, $\mathrm{P}<0.05 ; 2^{\#}, \mathrm{P}<0.01$; Fig. 3A middle and right). It is necessary to emphasize that the CHOP and hIAPP transgenes are exogenous; the CHOP transgene is murine and the hIAPP cDNA is human. These two genes were undetected in the control animals. The tissue specificities of the PapoE and PIP were also almost ideal (Fig. 3B and C). The mRNA expression levels of $11 \beta$-HSD1 in the livers of piglets $1^{\#}$ and $2^{\#}$ were marginally higher than in the muscle and kidneys (Fig. 3B and C; left). In addition, the expression levels of CHOP and hIAPP in the pancreas were higher, compared with those in the muscle and kidneys (Fig. 3B and $\mathrm{C}$; middle and right). The nonspecific expression in the other tissues may be to the selecting of specific promoters with their core regions for utility reasons, and these core regions can be involved in their specific tissues (29). These promoters may be expressed in other undesired organs or tissues due to certain intracellular transcription factors binding to the core region non-specifically, driving transgene expression (36). This issue requires consideration and investigation in the future.

Western blot analysis was used to detect protein expression levels, and to identify whether the protein specific levels of these factors were consistent with the mRNA expression levels (Fig. 3D). A doublet corresponding to $11 \beta$-HSD1 was observed in piglet $2^{\#}$; and this second band may represent the $\mathrm{Tg}$ expression protein or a splice variant of the $\mathrm{Tg}$ protein, compared with the Nc. Similar to the mRNA expression profile, hIAPP was expressed at a high level in the pancreas
Table III. Multi-transgene copy numbers.

\begin{tabular}{lccr}
\hline Gene & $1^{\#}$ & $2^{\#}$ & Negative control \\
\hline $11 \beta$-HSD1 & 12.16 & 10.09 & 0.41 \\
hIAPP & 40.52 & 28.01 & 0.01 \\
CHOP & 54.68 & 46.13 & $<0.01$ \\
\hline
\end{tabular}

Copy numbers of three genes in the $1^{\#}, 2^{\#}$ and negative control piglets Values are expressed as the mean of three measurements. 11 $\beta$-HSD1, $11-\beta$-hydroxysteroid dehydrogenase 1 ; CHOP, C/EBP homologous protein; IAPP, islet amyloid polypeptide.

A

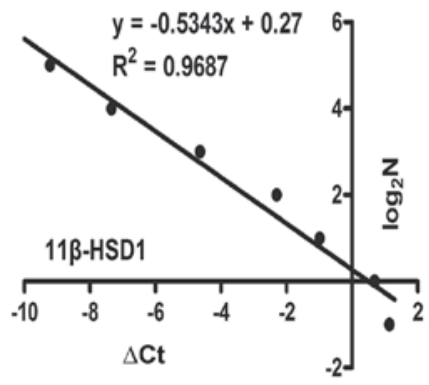

B

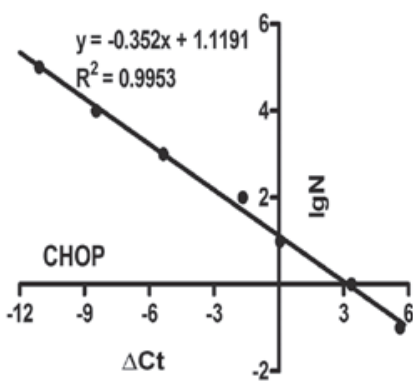

C

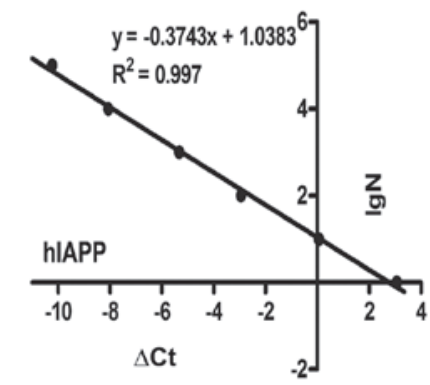

Figure 2. Analysis of transgenic copy numbers. Three standard curves showing copy number logarithms and corresponding $\Delta \mathrm{Ct}$ values for (A) $11 \beta-H S D 1$, (B) CHOP and (C) IAPP, respectively. 11 $\beta$-HSD1, 11- $\beta$-hydroxysteroid dehydrogenase 1; CHOP, C/EBP homologous protein; IAPP, islet amyloid polypeptide.

of the Tg piglets. Tg murine CHOP was observed at low levels in the pancreas. The present study then performed immunohistochemical analysis to validate the expression of CHOP (Fig. 4A; middle), and the results indicated that the hybridized intensities of CHOP in the Tg group were higher, compared with those of the Nc group.

Primary identification of function and associated phenotype. Due to the chronic nature of Type 2 diabetes, the blood 
A

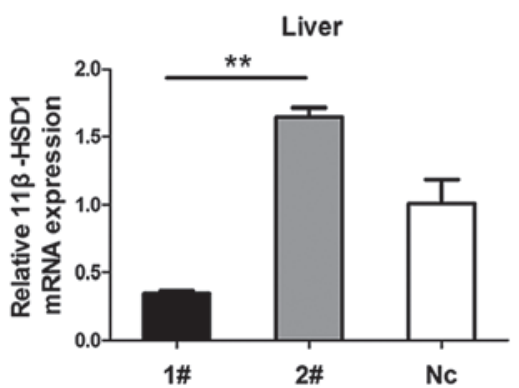

B

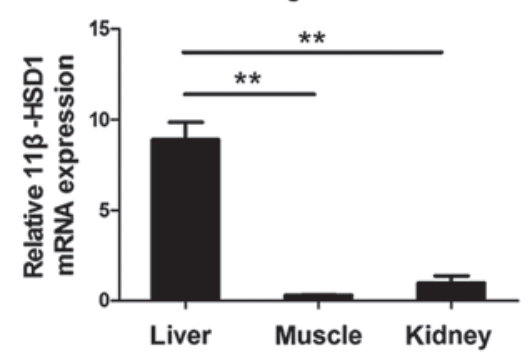

C

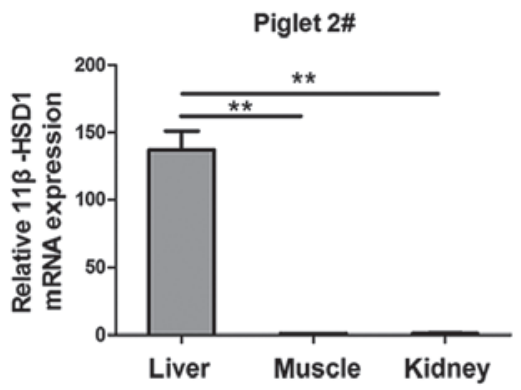

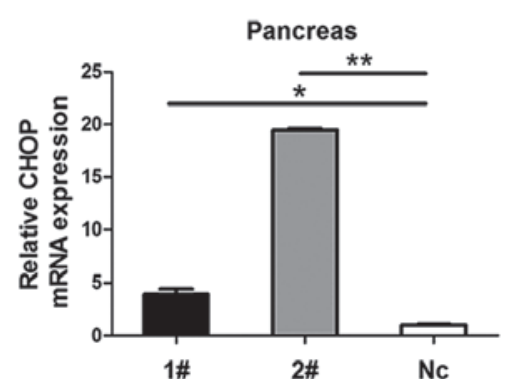

Piglet 1\#
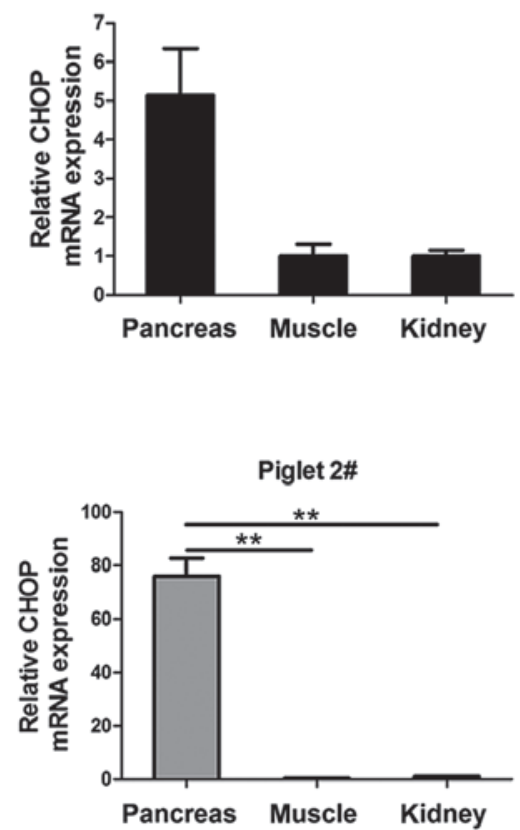
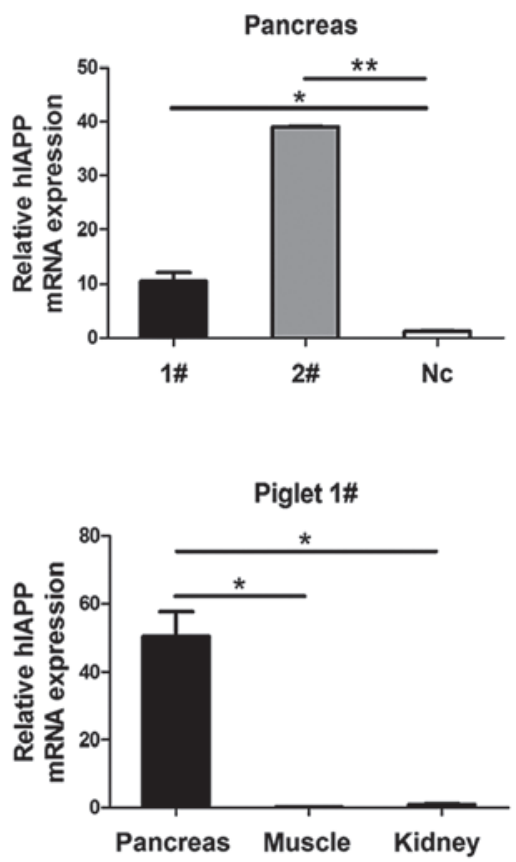

D

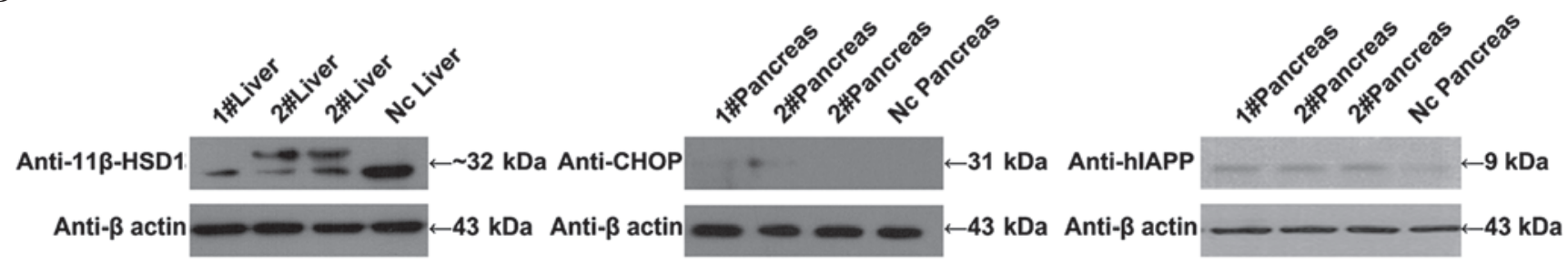

Figure 3. Protein expression and transgene expression analyses. (A) Expression levels of $11 \beta$-HSD1 in the liver of the $1^{\#}, 2^{\#}$ and Nc piglets. The mRNA of $1^{\#}$ liver was likely degraded, so that its relative expression was lower than in the Nc piglet. Expression levels of CHOP and hIAPP in the pancreas of the $1^{\#}$ and $2^{\#}$ pigs were greater than in Nc. (B and C) Specific expression levels in the liver were compared with those in the muscle and kidney of the same Tg piglet. The specific expression levels of CHOP and hIAPP in the pancreas were high, compared with the levels in the other tissues of the same Tg piglet. (D) Results of exogenous protein expression analysis. Transgenic $11 \beta \mathrm{HSD}-1$ was confirmed using a porcine polyclonal anti-11 $\beta$-HSD1 antibody in the liver of piglet $2^{\#}$. CHOP was detected at low levels in piglets $1^{\#}$ and $2^{\#}$, and was not detected in Nc using a monoclonal mouse anti-CHOP antibody. Transgenic hIAPP was overexpressed in the pancreas of piglets $1^{\#}$ and $2^{\#}$, as assessed using human polyclonal anti-hIAPP antibody. Each sample was analyzed in triplicate and the data are expressed as the mean \pm standard error of the mean $\left(\mathrm{n}=3\right.$, three parts of the tissue samples). ${ }^{*} \mathrm{P}<0.05 ;{ }^{* *} \mathrm{P}<0.01$. Tg, transgenic; $\mathrm{Nc}$, negative control; 1 $\beta$-HSD1, 11- $\beta$-hydroxysteroid dehydrogenase 1; CHOP, C/EBP homologous protein; hIAPP, human islet amyloid polypeptide.

glucose level of the Tg pig was normal. The Tg pig continually showed significant disease symptoms, and may have required an extended period. Future investigations may involve the induction of hyperglycemia with high-fat, high-calorie diets. However, notable original pathological changes were observed without neonatal hyperglycemia.
The results of the anti-insulin immunohistochemistry confirmed that the normal shapes of the islet cells were affected, and that their volume was reduced, compared with the normal islet cells in the Nc piglet (Fig. 4A; upper). The results suggested that the development of the islet of Langerhans in the $\mathrm{Tg}$ piglets was also impaired. In addition, the increase in 
A

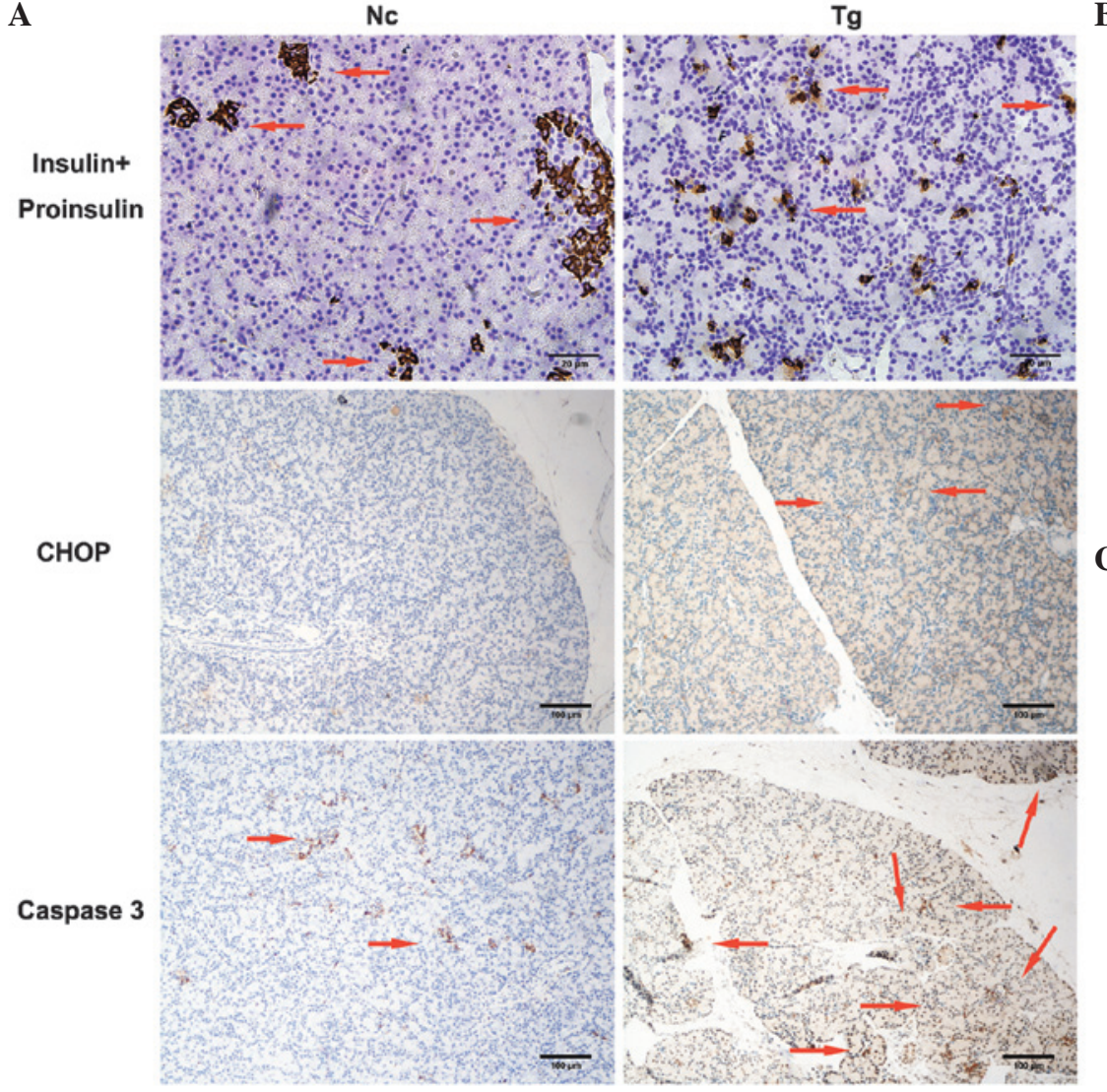

B
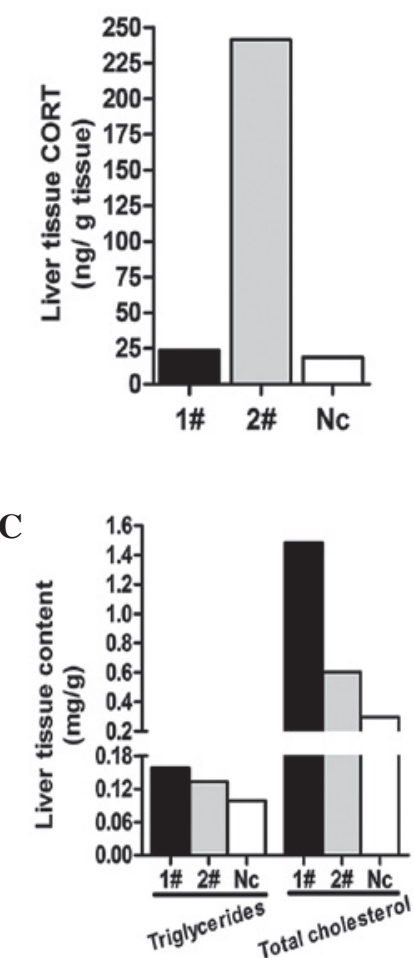

Figure 4. Phenotypic analysis. (A) Photomicrograph of pancreas immunohistochemistry. Tg piglet $2^{\#}$ and an Nc were sacrificed. Top row, insulin immunohistochemistry of the pancreases of Tg piglet $2^{\#}$ and $\mathrm{Nc}$ shows the status of islet cell development; observing the profile of the islet cells allows the estimation of $\beta$ cell proliferation (magnification, $\mathrm{x} 400$; scale bar $=20 \mu \mathrm{m})$. Middle row, pancreas sections stained with anti-CHOP antibody $(1: 50$; scale bar=100 $\mu \mathrm{m})$. Bottom row, positive caspase 3 signals show apoptosis in Tg piglet $2^{\#}$ and Nc (scale bar $=100 \mu \mathrm{m}$ ). (B) CORT, (C) triglyceride and total cholesterol concentrations were determined in the $\mathrm{Tg} 1^{\#}, \mathrm{Tg} 2^{\#}$ and Nc piglets. Expression of $11 \beta$-HSD1, $11-\beta$-hydroxysteroid dehydrogenase 1 in the Tg piglets led to an increase in CORT ( $2^{\#)}$. Subsequently, the hepatic lipid contents (triglycerides and total cholesterol) increased and exceeded those in the Nc piglet. These values were measured twice and are expressed as the mean. Tg, transgenic; Nc, negative control; CHOP, C/EBP homologous protein; CORT, cortisol.

the active form of caspase 3 is used as an indicator of cell apoptosis (37). In the present study caspase 3 immunohistochemistry revealed increasing apoptosis (Fig. 4A; lower). Consequently, it was reasonable to hypothesize that coexpression of the two genes in the pancreas enhanced the decline in insulin secretion (38).

The 11 $\beta$-HSD1 gene expresses the enzyme, $11-\beta$-hydroxysteroid dehydrogenase 1 , which can catalyze the activation of cortisone to an active glucocorticoid (cortisol) (20,31). Subsequently, it can facilitate the lipid content generation of triglycerides and total cholesterol $(26,39)$. $11 \beta$-HSD1 can accelerate liver adipose tissue accumulation and lead to insulin resistance $(24,40)$. In the present study, piglet $2^{\#}$ was neonatal, and no clear adipose vacuoles were visualized in the HE sections. Therefore, the liver tissue cortisol (Fig. 4B), triglyceride and total cholesterol (Fig. 4C) contents were determined. The $\mathrm{Tg}$ piglets had higher levels of these factors, compared with the Nc piglet. The cortisol level of piglet $2^{\#}$ was high, and the triglyceride and total cholesterol levels of piglet $1^{\#}$ were marginally higher than those of piglet $2^{\#}$. Although these differences between the two Tg piglets were observed, it is important to note that the $1^{\#}$ and $2^{\#} \mathrm{Tg}$ piglets had higher levels of cortisol, triglyceride and total cholesterol contents, compared with the Nc piglet. These results also preliminarily verified the effect of $11 \beta$-HSD1 overexpression, and suggested that $11 \beta-H S D 1$ was more likely to induce insulin resistance in the near future.

\section{Discussion}

Based on the complicated pathogenesis of type 2 diabetes, the present study hypothesized that a multi-transgenic pig model, generated by directly altering relevant genes to cause insulin resistance and affect insulin secretion, can be used to provide a suitable mimic of diabetes. This was encouraged following the success of single-transgene pig diabetes models $(3,17-19)$. These previous studies showed that single genes or factors affected the molecular pathogenesis of diabetes. However, these single genes were circumscribed, and their effectiveness was limited by compensatory mechanisms. In particular, although the pancreas is the pathological center of diabetes, the disease also involves a variety of peripheral tissues, including the liver and muscles (41). Therefore, the selection of relevant genes in the present study was based on this consideration. 11 $\beta$-HSD1 is important in insulin resistance. Previous studies have reported that the constitutive overexpression of $11 \beta-H S D 1$ can induce insulin resistance with metabolic syndrome in rodents. Masuzaki et al created Tg mice overexpressing 11 $\beta$-HSD1 
selectively in adipose tissue. These mice developed visceral obesity, which was exaggerated by a high-fat diet as a result of increased adipose levels of corticosterone. In addition, the mice also exhibited hyperphagia with hyperleptinemia, marked insulin resistance and hyperlipidemia (20). Paterson et al generated $\mathrm{Tg}$ mice selectively, showing increased activity of $11 \beta-H S D 1$ in the liver. These animals exhibited fatty liver, dyslipidemia, transgene-dose-associated hypertension and insulin resistance, but retained normal body weight (24). It has also been hypothesized that the exclusive overexpression of $11 \beta-H S D 1$ may be desirable for generating a porcine model of insulin resistance $(42,43)$. In addition, the hIAPP gene encodes islet amyloid polypeptide, which is known to precipitate in the islet $\beta$ cells of patients with diabetes (44). This polypeptide can induce $\beta$ cell apoptosis, however, it is unclear whether hIAPP deposition and accumulation in porcine $\beta$ cells has this effect (3). Several studies have prepared hIAPP Tg mice and demonstrated the viability of this method. For example, Hull et al produced hIAPP Tg lines, which showed islet amyloid formation and $\beta$-cell loss when fed high-fat diets (45), and diabetes experts have suggested that genetically engineered hIAPP Tg pigs are suitable for mimicking the role of islet amyloidosis in the pathogenesis of type 2 diabetes mellitus pathogenesis (3). In addition, CHOP is a direct upstream factor, which can drive endoplasmic reticulum stress and cell apoptosis (46). It has been reported that, in pancreatic $\beta$-cells, endoplasmic reticulum stress-mediated apoptosis is associated with the pathogenesis of diabetes (47). The present study hypothesized that co-expressing hIAPP and CHOP in the pancreas exaggerates the $\beta$-cell apoptosis-inducing effect, and that the multi-transgenic piglets generated in the present study using a tissue-specific polycistronic system provide ideal animal models of diabetes, possibly conferring insulin resistance accompanied by declining insulin secretion. The use of multiple genes involved in these two predominant modes of pathogeneses provides an advantage over single-Tg diabetes pig models. In addition, the primary data obtained in the presents study indicated that the functional gene polycistronic system was feasible. Hepatic lipid biochemistry and immunohistochemistry indicated that $\mathrm{Tg}$ hepatic lipogenesis was facilitated, that islets of Langerhans were impaired and that insulin secretion was likely to be affected, which may be attributed to cooperation between CHOP and hIAPP.

Compared with previous single-vector multi-transgenic pigs $(12,15)$, the primary advantage of the multi-transgenic approach is that diabetes-associated genes involving the molecular pathogenesis of diabetes were selected. The results of the present study verified the hypothesis that replacing marker genes with functional genes is achievable. The second advantage is that the present study did not perform gene replacement only. Whereas other studies have used CMV or CMV early enhancer/chicken $\beta$-actin promoters, which are expressed ubiquitously in vivo, the present study used two different tissue-specific porcine promoters, and qPCR assays ensured that these promoters were expressed in their target organs. Western blotting and immunohistochemistry also detected the expression of the Tg proteins to a certain extent. In particular, PapoE was cloned (29), and the MAR insulator was placed between the expression cassettes to reduce the impact of the promoters (28). The third advantage is that, to eliminate the $2 \mathrm{~A}$ tail, which may affect the function of the upstream protein, a furin cleavage site was added. Furin, an endogenous proprotein convertase, can cut $2 \mathrm{~A}$ tails (12), and the successful utilization of furin was previously reported in pigs (11). $2 \mathrm{~A}$ is a superior polycistronic system, compard with IRES (12). Jeong et al used an IRES-mediated vector co-expressing xenotransplant genes in minipigs. However, hCD55 was not expressed (15). Of note, the present study unexpectedly observed that the copy numbers of the three genes were not the same, and there are no previous reports regarding copy numbers in singular polycistronic pigs. This result may be due to random transgenes exhibiting different positional effects, or it may indicate that the linear vector used in the present study was fragmented, and that the integrating capacity of the segments was different. The exact reasons for these observations require further investigation. Therefore, copy number is a significant element that requires consideration when manufacturing multi-transgenic pigs and subsequently constructing their colony.

In conclusion, the present study suggested that the Tg pig model constructed had functional transgenes and possessed the desired diabetes-associated phenotypes. The merit of this system was its targeted multi-transgene expression. The results demonstrateda technique for how to co-express multiple functional genes in specific tissues, in contrast to impractical marker genes or ubiquitous gene expression. The original aim of the present study was to examine comprehensive pathogenesis in multi-transgenic pig models to develop novel strategies for how to more reasonably mimic a human polygenic disease. Several questions remain to be answered, however, the initial phenotypes indicated that $\mathrm{Tg}$ animals with multiple functional genes are promising and have significant potential. Prospectively, diabetes multi-transgenic models may be suitable for diverse drug development, from peripheral insulin resistance to central relative decreases in insulin secretion.

\section{Acknowledgements}

This study was supported by the National Natural Science Foundation of China (grant.no. 31372276), the National Science and Technology Major Project (grant. no. 2013ZX08010-003), the Development Program of China (grant. no.2012AA020603) and the Agricultural Science and Technology Innovation Program (grant. nos. ASTIP-IAS05 and ASTIP-IAS-TS-4).

\section{References}

1. American Diabetes Association: Diagnosis and classification of diabetes mellitus. Diabetes care 36 (Suppl 1): S67-S74, 2013.

2. Masiello P: Animal models of type 2 diabetes with reduced pancreatic beta-cell mass. Int $\mathrm{J}$ Biochem Cell Biol 38: 873-893, 2006.

3. Wolf E, Braun-Reichhart C, Streckel E and Renner S: Genetically engineered pig models for diabetes research. Transgenic Res 23: 27-38, 2014.

4. Rüster C and Wolf G: Models of diabetic nephropathy. Drug discovery today: Disease models 7: 35-41, 2010.

5. Verma N, Rettenmeier AW and Schmitz-Spanke S: Recent advances in the use of Sus scrofa (pig) as a model system for proteomic studies. Proteomics 11: 776-793, 2011.

6. Liu H, Li Y, Wei Q, Liu C, Bolund L, Vajta G, Dou H, Yang W, $\mathrm{Xu} \mathrm{Y}$, Luan J, et al: Development of transgenic minipigs with expression of antimorphic human cryptochrome 1. PLoS One 8: e76098, 2013. 
7. Xia JH, Yuan J, Xin LL, Zhang Y, Kong S, Chen Y, Yang S and $\mathrm{Li} \mathrm{K}$ : Transcriptome analysis on the inflammatory cell infiltration of nonalcoholic steatohepatitis in Bama minipigs induced by a long-term high-fat, high-sucrose diet. Plos One 9: e113724, 2014.

8. Xia JH, Zhang YY, Xin LL, Kong S, Chen Y, Yang S and Li K: Global Transcriptomic Profiling of Cardiac Hypertrophy and Fatty Heart Induced by Long-Term High-Energy Diet in Bama Miniature Pigs. Plos One 10: e0132420, 2015.

9. Yang SL, Xia JH, Zhang YY, Fan JG, Wang H, Yuan J, Zhao ZZ, Pan Q, Mu YL, Xin LL, Chen YX and Li K: Hyperinsulinemia shifted energy supply from glucose to ketone bodies in early nonalcoholic steatohepatitis from high-fat high-sucrose diet induced Bama minipigs. Sci Rep 5: 13980, 2015.

10. Winzell MS and Ahrén B: The high-fat diet-fed mouse - A model for studying mechanisms and treatment of impaired glucose tolerance and type 2 diabetes. Diabetes 53: S215-S219, 2004.

11. Danda RS, Habiba NM, Rincon-Choles H, Bhandari BK, Barnes JL, Abboud HE and Pergola PE: Kidney involvemen in a nongenetic rat model of type 2 diabetes. Kidney Int 68 2562-2571, 2005

12. Deng W, Yang D, Zhao B, Ouyang Z, Song J, Fan N, Liu Z, Zhao Y, Wu Q, Nashun B, et al: Use of the $2 \mathrm{~A}$ peptide for generation of multi-transgenic pigs through a single round of nuclear transfer. PLoS One 6: e19986, 2011.

13. Dieckhoff B, Kessler B, Jobst D, Kues W, Petersen B, Pfeifer A Kurth R, Niemann H, Wolf E and Denner J: Distribution and expression of porcine endogenous retroviruses in multi-transgenic pigs generated for xenotransplantation. Xenotransplantation 16 : 64-73, 2009.

14. Webster NL, Forni M, Bacci ML, Giovannoni R, Razzini R, Fantinati $\mathrm{P}$, Zannoni A, Fusetti L, Dalprà L, Bianco MR, et al: Multi-transgenic pigs expressing three fluorescent proteins produced with high efficiency by sperm mediated gene transfer. Mol Reprod Dev 72: 68-76, 2005.

15. Jeong YH, Park CH, Jang GH, Jeong YI, Hwang IS, Jeong YW, Kim YK, Shin T, Kim NH, Hyun SH, et al: Production of multiple transgenic Yucatan miniature pigs expressing human complement regulatory factors, human CD55, CD59 and H-transferase genes. PLoS One 8: e63241, 2013.

16. Park SJ, Cho B, Koo OJ, Kim H, Kang JT, Hurh S, Kim SJ, Yeom HJ, Moon J, Lee EM, et al: Production and characterization of soluble human TNFRI-Fc and human HO-1 (HMOX1) transgenic pigs by using the F2A peptide. Transgenic Res 23 407-419, 2014

17. Renner S, Braun-Reichhart C, Blutke A, Herbach N, Emrich D, Streckel E, Wünsch A, Kessler B, Kurome M, Bähr A, et al: Permanent neonatal diabetes in INS (C94Y) transgenic pigs. Diabetes 62: 1505-1511, 2013.

18. Umeyama K, Watanabe M, Saito H, Kurome M, Tohi S, Matsunari H, Miki K and Nagashima H: Dominant-negative mutant hepatocyte nuclear factor 1alpha induces diabetes in transgenic-cloned pigs. Transgenic Res 18: 697-706, 2009.

19. Renner S, Fehlings C, Herbach N, Hofmann A, von Waldthausen DC, Kessler B, Ulrichs K, Chodnevskaja I, Moskalenko V, Amselgruber W, et al: Glucose intolerance and reduced proliferation of pancreatic beta-cells in transgenic pigs with impaired glucose-dependent insulinotropic polypeptide function. Diabetes 59: 1228-1238, 2010

20. Masuzaki H, Paterson J, Shinyama H, Morton NM, Mullins JJ, Seckl JR and Flier JS: A transgenic model of visceral obesity and the metabolic syndrome. Science 294: 2166-2170, 2001.

21. Mathis D, Vence L and Benoist C: beta-cell death during progression to diabetes. Nature 414: 792-798, 2001.

22. Maris M, Overbergh L, Gysemans C, Waget A, Cardozo AK, Verdrengh E, Cunha JP, Gotoh T, Cnop M, et al: Deletion of $\mathrm{C} / \mathrm{EBP}$ homologous protein (Chop) in $\mathrm{C} 57 \mathrm{Bl} / 6$ mice dissociates obesity from insulin resistance. Diabetologia 55: 1167-1178, 2012.

23. Hoppener JWM, Jacobs HM, Wierup N, Sotthewes G, Sprong M, de Vos P, Berger R, Sundler F and Ahrén B: Human islet amyloid polypeptide transgenic mice: In vivo and ex vivo models for the role of hIAPP in type 2 diabetes mellitus. Exp Diabetes Res 2008: 697035, 2008.

24. Paterson JM, Morton NM, Fievet C, Kenyon CJ, Holmes MC, Staels B, Seckl JR and Mullins JJ: Metabolic syndrome without obesity: Hepatic overexpression of 11beta-hydroxysteroid dehydrogenase type 1 in transgenic mice. Proc Natl Acad Sci USA 101: 7088-7093, 2004
25. Hull RL, Shen ZP, Watts MR, Kodama K, Carr DB, Utzschneider KM, Zraika S, Wang F and Kahn SE: Long-term treatment with rosiglitazone and metformin reduces the extent of, but does not prevent, islet antyloid deposition in mice expressing the gene for human islet antyloid polypeptide. Diabetes 54 2235-2244, 2005

26. Masuzaki H and Flier JS: Tissue-specific glucocorticoid reactivating enzyme, 11 beta-hydroxysteroid dehydrogenase type 1 (11 beta-HSD1) - a promising drug target for the treatment of metabolic syndrome. Curr Drug Targets Immune Endocr Metabol Disord 3: 255-262, 2003.

27. Chen ZY, Liu SN, Li CN, et al: Atorvastatin helps preserve pancreatic beta cell function in obese C57BL/6 J mice and the effect is related to increased pancreas proliferation and amelioration of endoplasmic-reticulum stress. Lipids Health Dis 13: 2014.

28. West AG, Gaszner M and Felsenfeld G: Insulators: Many functions, many mechanisms. Genes Dev 16: 271-288, 2002.

29. Xia J, Hu B, Mu Y, Xin L, Yang S and Li K: Molecular cloning and characterization of the promoter region of the porcine apolipoprotein E gene. Mol Biol Rep 41: 3211-3217, 2014.

30. Ruan JX, Li HG, Xu K, Wu T, Wei J, Zhou R, Liu Z, Mu Y, Yang S, Ouyang H, et al: Highly efficient CRISPR/Cas9-mediated transgene knockin at the H11 locus in pigs. Sci Rep 5: 14253 , 2015.

31. Lai L, Kolber-Simonds D, Park KW, Cheong HT, Greenstein JL, Im GS, Samuel M, Bonk A, Rieke A, Day BN, et al: Production of alpha-1,3-galactosyltransferase knockout pigs by nuclear transfer cloning. Science 295: 1089-1092, 2002.

32. Livak KJ and Schmittgen TD: Analysis of relative gene expression data using real-time quantitative PCR and the 2(T)(-Delta Delta C) method. Methods 25: 402-408, 2001.

33. Bubner B and Baldwin IT: Use of real-time PCR for determining copy number and zygosity in transgenic plants. Plant Cell Rep 23: 263-271, 2004

34. Luo W, Li Z, Huang Y, Han Y, Yao C, Duan X, Ouyang H and Li L: Generation of AQP2-Cre transgenic mini-pigs specifically expressing Cre recombinase in kidney collecting duct cells. Transgenic Res 23: 365-375, 2014

35. Li L, Li Q, Bao Y, Li J, Chen Z, Yu X, Zhao Y, Tian K and Li N: RNAi-based inhibition of porcine reproductive and respiratory syndrome virus replication in transgenic pigs. J Biotechnol 171: 17-24, 2014.

36. Zhang Y, Wong CH, Birnbaum RY, Li G, Favaro R, Ngan CY, Lim J, Tai E, Poh HM, Wong E, et al: Chromatin connectivity maps reveal dynamic promoter-enhancer long-range associations. Nature 504: 306-310, 2013.

37. Sadeghnia HR, Ghorbani Hesari T, Mortazavian SM, Mousavi SH, Tayarani-Najaran Z and Ghorbani A: Viola tricolor induces apoptosis in cancer cells and exhibits antiangiogenic activity on chicken chorioallantoic membrane. Biomed Res Int 2014: 625792, 2014

38. Rabhi N, Salas E, Froguel P and Annicotte JS: Role of the unfolded protein response in $\beta$ cell compensation and failure during diabetes. J Diabetes Res 2014: 795171, 2014.

39. Morton NM, Paterson JM, Masuzaki H, Holmes MC, Staels B, Fievet C, Walker BR, Flier JS, Mullins JJ and Seckl JR: Novel adipose tissue-mediated resistance to diet-induced visceral obesity in 11 beta-hydroxysteroid dehydrogenase type 1-deficient mice. Diabetes 53: 931-938, 2004.

40. Paterson JM, Holmes MC, Kenyon CJ, Carter R, Mullins JJ and Seckl JR: Liver-selective transgene rescue of hypothalamic-pituitary-adrenal axis dysfunction in 11 beta-hydroxysteroid dehydrogenase type 1-deficient mice. Endocrinology 148: 961-966, 2007

41. Lee AW and Cox RD: Use of mouse models in studying type 2 diabetes mellitus. Expert Rev Mol Med 13: e1, 2011.

42. Jung EM, An BS, Kim YK, Jeong YH, Hwang WS and Jeung EB: Generation of porcine fibroblasts overexpressing $11 \beta$-HSD1 with adipose tissue-specific aP2 promoter as a porcine model of metabolic syndrome. Mol Med Rep 8: 751-756, 2013.

43. Jeon Y, Kim Y, Yoon J, Cai L, Hwang SU, Kim E, Lee S, Jeung EB and Hyun SH: Production of $11 \beta$-hydroxysteroid dehydrogenase type 1 (11 $\beta$-HSD1) over-expressed pigs for the study of metabolic syndrome disease. Reprod Fertil Dev 26: 116-116, 2014. 
44. Bram Y, Frydman-Marom A, Yanai I, Gilead S, Shaltiel-Karyo R, Amdursky N, Gazit E: Apoptosis induced by islet amyloid polypeptide soluble oligomers is neutralized by diabetes-associated specific antibodies. Sci Rep 4: 4267, 2014.

45. Hull RL, Andrikopoulos S, Verchere CB, Vidal J, Wang F, Cnop M, Prigeon RL and Kahn SE: Increased dietary fat promotes islet amyloid formation and beta-cell secretory dysfunction in a transgenic mouse model of islet amyloid. Diabetes 52: 372-379, 2003.
46. Oyadomari S and Mori M: Roles of CHOP/GADD153 in endoplasmic reticulum stress. Cell Death Differ 11: 381-389, 2004.

47. Marchetti P, Bugliani M, Lupi R, Marselli L, Masini M, Boggi U, Filipponi F, Weir GC, Eizirik DL and Cnop M: The endoplasmic reticulum in pancreatic beta cells of type 2 diabetes patients. Diabetologia 50: 2486-2494, 2007. 